\title{
REGRAS PARA O TRATO VIRTUOSO DAS VESTES NA CASTELA DOS SÉCULOS XIV E XV
}

\author{
RULES FOR THE VIRTUOUS USAGE OF VESTS IN THE CASTILE \\ OF THE XIV AND XV CENTURY
}

Thiago Henrique Alvarado ${ }^{1}$

\begin{abstract}
RESUMO: Entre os séculos XIV e XV, as vestimentas de leigos e eclesiásticos receberam atenção significativa nos escritos de religiosos e clérigos, configurando-se como um dos eixos edificantes das condutas dos castelhanos. Tais escritos, compostos de tratados morais, manuais de confissão e textos devocionais redigidos originalmente em vernáculo ou em latim, foram traduzidos ou circularam no reino de Castela com o objetivo de estabelecer regras virtuosas e convenientes em relação ao vestir. A partir das considerações sobre as vestimentas presentes nesses escritos, pretende-se compreender as aproximações valorativas entre o vestir de leigos, eclesiásticos e religiosos, bem como as suas especificidades. Interessa, portanto, compreender como as prescrições e consequentes reiterações buscaram fixar entre os castelhanos um quadro de condutas cristão sobre o vestir
\end{abstract}

PALAVRAS-CHAVE: Castela; vestimentas; escritos religiosos

ABSTRACT: Between the fourteenth and fifteenth centuries, the laymen and ecclesiastics' garb received significant attention in religious and clerics' writings, becoming one of the building blocks of the Castilian demeanor. Such writings, composed of moral treaties, confession manuals and devotional texts originally written in vernacular or in latin, were translated or circulated in the kingdom of Castile with the purpose of establishing virtuous and convenient rules regarding dress code. Upon the considerations on the clothes present in these writings, it is intended to comprehend the evaluative approaches between the way laymen, ecclesiastics and religious dressed, as well as their specificity. Therefore, it is important to understand how the prescriptions and subsequent reiteration sought to establish a framework of Christian dress code among the Castilians.

KEYWORDS: Castile; clothes; religious writings

\footnotetext{
* Este artigo é resultado parcial de pesquisa de doutoramento a ser concluída em 2021, financiada pela FAPESP/CAPES (processo 17/01502-0) e realizada sob orientação da Prof ${ }^{a}$. $D^{a}$. Susani Silveira Lemos França. O artigo foi desenvolvido no âmbito do Projeto Temático "Escritos sobre os Novos Mundos" (Processo FAPESP 13/14786 -6).

1 Doutorando em História pelo Programa de Pós-Graduação em História da Universidade Estadual Paulista (UNESP), campus de Franca. Bolsista FAPESP/CAPES. Endereço profissional: Av. Eufrásia Monteiro Petráglia, 900, Jd. Dr. Antonio Petráglia, Franca/SP. CEP 14409-160. Telefone: (16) 3706-8700. E-mail: thiagoalvarado@gmail.com
} 
Introdução

Em 1477, frei Hernando de Talavera (1428-1507), religioso hieronimita e confessor de D. Isabel de Castela (1451-1504), * decidiu, após uma contenda entre o prelado ${ }^{2}$ da vila e os varões e as mulheres que traziam consigo trajes desonestos, escrever seu Tractado prouechoso que demuestra como en el vestir e calçar comunmente se cometen muchos pecados, y aun tanbien en el comer $y$ en el beuer. ${ }^{3}$ Segundo o prelado, a desonestidade no vestir era tal que fez com que Deus, com disciplina ${ }^{4}$ e açoite, castigasse os povos, 'especialmente a região de Terra de Campos' (Valladolid), com 'grande esterilidade' (TALAVERA, 2001: 21). ${ }^{5}$ Com o intuito de emendar as faltas, o prelado de Valladolid teria sentenciado os varões - que traziam camisa com os cabeções trabalhados - e as mulheres - que vestiam verdugos ${ }^{6}$ - ao desterro, ao pagamento de penas pecuniárias e à excomunhão maior; penas essas, aliás, igualmente imputáveis aos costureiros que contribuíssem com tais práticas pecaminosas (TALAVERA, 2001: 27) - sentenças essas que teriam provocado o questionamento dos varões e das mulheres quanto à interferência dos eclesiásticos no tocante às vestimentas dos leigos. Corroborando a perspectiva do prelado e com o objetivo de assegurar o vestir e o calçar entre as atividades a serem observadas por todos os cristãos a fim de terem uma vida virtuosa, Talavera redigiu aquele que viria a

\footnotetext{
* As citações do original castelhano foram traduzidas livremente pelo autor.

${ }^{2}$ Há uma diferença nas versões manuscrita e impressa. No manuscrito, a determinação partia dos 'veneráveis provisores, por outros veneráveis padres e honoráveis senhores para isso deputados' (TALAVERA, 14--: f. 38v). No incunábulo, por sua vez, indicava-se apenas o 'prelado eclesiástico' (TALAVERA, 2001: 27).

${ }^{3} \mathrm{O}$ tratado foi escrito enquanto Talavera ainda era prior do monastério de Santa Maria de Prado, extramuros de Valladolid, e impresso em 1496, quando já era arcebispo de Granada. O incunábulo conta com uma série de escritos de Talavera, entre os quais um manual de confissão e um tratado sobre o murmurar. Utiliza-se, aqui, a edição realizada por Teresa de Castro (2001: 11-92), que coteja as versões manuscrita e impressa. Sobre a atuação do religioso e seu tratado ver o estudo introdutório de Teresa de Castro (2001: 11-20).

${ }^{4}$ Disciplina parece empregar-se, neste caso, na acepção de 'açoite de penitente' (DISCÍPULO, 1987: 216).

${ }^{5}$ Sobre o assunto, ver: PARRILLA, 2015: não paginado.

${ }^{6}$ Os cabeções lavrados correspondem às golas adornadas, e os verdugos a longos vestidos cosidos por baixo com aros. Sobre essas vestimentas em Castela de finais da Idade Média, ver o estudo de BERNÍS MADRAZO, 1978, v. 1.
} 
constituir o mais significativo escrito edificante sobre o vestir em Castela durante o século XV.

A preocupação com as mudanças e os excessos nas vestimentas, quer de varões e mulheres, quer de leigos e religiosos, foi igualmente partilhada por outros tratadistas na Castela dos séculos XIV e XV. Provenientes sobretudo de ordens religiosas, em que a honestidade e a austeridade do hábito ocupavam lugares centrais, esses homens propuseram aos seus leitores e ouvintes modos de conduta adequados em relação ao vestir. Embora esses letrados não tenham dedicado arrazoado mais denso à temática, nem ratificado penas semelhantes às propostas pelo prelado vallisoletano, não deixaram, porém, de legar em seus escritos algumas observações e prescrições à maneira de vestir-se, aspecto da vida que, desde longa data, configurava um dos eixos edificantes dos cristãos.

Entre os tratadistas que se dedicaram a escrever algumas linhas prescritivas sobre as vestimentas, cujos textos circularam entre os castelhanos, encontravam-se os nomes dos franciscanos Juan García de Castrojeriz (século XIV), Álvaro Pais (c.1275-1352) e Ambrósio de Montesino (c.1444-1514), do agostiniano Martín de Córdoba (?-1476), do dominicano Juan López de Salamanca (1390-1460), do já citado hieronimita Hernando de Talavera, do bispo de Ávila, D. Afonso de Madrigal (c.1410-1455), o 'Tostado', e o do arcediago de Leão, Clemente Sánchez de Vercial (c.1370-1438). Eclesiásticos, portanto, que congregavam muitas vezes atividades pastorais, docentes nas universidades e de aconselhamento régio, além de atuarem como confessores régios ou nobiliárquicos. Por meio de um amplo conjunto de escritos - tais como a tradução e a glosa realizada por García de Castrojeriz, a pedido do bispo de Osma, da célebre obra do agostiniano Egídio Romano, ou Gil de Roma (c.1243-1316), para a instrução do príncipe D. Pedro (1334-1369) (GLOSA, 2005), ${ }^{7}$ futuro Pedro I de Castela; a correção da tradução da Vita Christi, do franciscano catalão Francesc Eiximenis (1330-1409) (EIXIMENIS, 1496), realizada por Talavera, e a tradução da igualmente célebre Vita Christi do

\footnotetext{
${ }^{7}$ A autoria da glosa e da tradução tem sido questionada pelos estudiosos. Sobre a discussão, ver: DÍEZ GARRETAS; FRADEJAS RUEDA; ACERO DURÁNTEZ, 2004.
} 
cartuxo Ludolfo de Saxônia (c.1300-c.1377), realizada por Montesino a pedido da rainha D. Isabel (LUDOLPHUS DE SAXONIA, 1502-1503) -, esses religiosos contribuíram para a difusão, em solo castelhano, de passagens em que afirmavam ser possível reconhecer práticas virtuosas ou pecaminosas por meio das vestes de homens e mulheres. A esses textos, somavam-se outros tantos escritos diversos, como os Evangelios moralizados de Juan López de Salamanca (LÓPEZ DE SALAMANCA, 2004), dedicados a fornecer um repertório ao clero para sua pregação; o Comento o exposición de Eusebio de las cronicas o tiempos interpretado en vulgar, o Confesional del Tostado e as suas Catorce questiones, de D. Afonso de Madrigal (MADRIGAL, 1500; MADRIGAL, 1507; MADRIGAL, 1551), e o próprio Tratado provechoso de Talavera.

A partir, portanto, deste corpus documental, constituído de escritos produzidos por eclesiásticos, e de notória preocupação edificante, pretende-se compreender o estabelecimento de valores que conduziram o vestir de homens e mulheres castelhanos entre os séculos XIV e XV. Desse modo, não é objetivo questionar se tais valores foram seguidos ou não, mas sim o de analisar a afirmação de determinados pactos acerca do vestir, que tiveram larga difusão e notável recorrência em escritos diversos. Portanto, interessa aqui particularmente, por meio de escritos diversos de eclesiásticos, abordar a construção e a afirmação de determinados valores morais pelos quais os castelhanos deveriam conduzir-se em relação às vestimentas. ${ }^{8}$

A despeito de os leigos também escreverem sobre a temática e estabelecerem leis, como foi o caso dos monarcas desde o século XIII (GONZÁLEZ ARCE, 1988), foram os escritos dos eclesiásticos aqueles que, entre os séculos XIV e XV, apresentavam uma síntese mais acabada dos valores sobre o vestir. Esses letrados levavam sempre em considerações as implicações teológicas do vestir, e elaboravam explanações mais extensas para se compor um quadro de vícios e virtudes. Quanto a este quadro de valores, vale retomar

\footnotetext{
${ }^{8}$ Trata-se, aqui, de uma perspectiva partilhada pelo Grupo Temático "Escritos sobre os Novos Mundos: uma história da construção de valores morais em língua portuguesa", financiado pela FAPESP (13/14786-6). https://www2.unesp.br/portal\#!/escritos
} 
as justificativas dadas pelos moradores da vila de Valladolid, e recolhidas por Talavera em seu tratado, para contraporem-se às penas aplicadas pelo prelado, pois fornecem importantes indicativos da percepção de muitos leigos e eclesiásticos a respeito das vestimentas em finais da Idade Média.

As penas aplicadas pelo prelado vallisoletano aos que trouxessem vestes desonestas, segundo Talavera, fizeram com que os varões e, especialmente, as mulheres da vila - tidas por mais propensas a questionar as autoridades confrontassem as decisões e questionassem os limites da atuação dos eclesiásticos quanto às vestes dos leigos, alegando que: não haveria regra certa para o vestir; as pessoas se vestiriam de maneira distinta em cada região e segundo seus gostos; não haveria pecado, sobretudo mortal, que justificasse a excomunhão maior. Para o hieronimita, por sua vez, haveria regras para o vestir, as quais, se não fossem seguidas, poderiam ocasionar diversos pecados e males, o que justificava a própria intervenção dos eclesiásticos na vida dos laicos (TALAVERA, 2001: 28). Sendo assim, todos os reitores e prelados não apenas podiam, mas deviam 'ordenar e pôr acerca [dos trajes] lei e leis', com o intuito de quitar 'as causas e as ocasiões dos pecados' e, por conseguinte, contribuir para tornar os súditos e cidadãos 'justos, virtuosos e bons' (TALAVERA, 2001: 56).

A proposição de Talavera, apesar de partir de uma questão específica, extrapolava aquele momento e propunha questões para todos os cristãos, além de afirmar a intervenção de eclesiásticos nos assuntos laicos, notadamente nas vestimentas. Ainda que fosse possível constatar uma preocupação com as vestimentas dos cristãos, e mais incisivamente das cristãs, desde os Apóstolos Paulo (1 Tm 2, 9-10) e Pedro (1 Pe 3, 1-6), passando pelos Padres da Igreja, como são Cipriano de Cartago (c.200-258) e Tertuliano de Cartago (c.155c.240), entre outros tratadistas cristãos estimados ao longo de toda a Idade Média, para não falar dos antigos, igualmente rememorados pelos tratadistas medievais, ${ }^{9}$ foi no século XIII, nos territórios de Castela, que a atenção de

\footnotetext{
9 Para algumas considerações mais amplas sobre as vestimentas na Idade Média, ver: BARTHOLEYNS, 2007: 219-257; BARTHOLEYNS, 2009. Sobre alguns dos referenciais bíblicos, ver: CRAS, 2011.
} 
laicos e eclesiásticos às vestimentas passou a ser mais significativa (GONZÁLEZ ARCE, 1998). A partir dessa centúria, com o estabelecimento de rotas comerciais, o desenvolvimento das cidades e vilas e dos ofícios relacionados ao vestir, houve larga circulação de bens preciosos e de novas peças de vestir, que provocaram reações de laicos, em particular o monarca D. Afonso X (1221-1284), preocupado com os gastos excessivos e a eventual confusão entre estados distintos. ${ }^{10}$ Concomitante à circulação maior de vestimentas, panos, materiais, peles e adornos, deu-se aquela dos novos trajes, com especial ênfase no século XIV.

\section{Os homens e as vestimentas}

Nos reinos cristãos do Ocidente, até o século XIII, as diferenças entre as vestimentas de homens e mulheres não eram muito significativas. Ambos vestiam uma espécie de túnica, chamada saya, em castelhano, sempre maior para as mulheres, alcançando seus pés e calcanhares, e menor para os homens, atingindo pouco abaixo dos joelhos (BERNÍS MADRAZO, 1955: 26). A distinção entre as vestes de varões e mulheres leigos acentuou-se, em meados do XIV, com o surgimento da veste curta dos varões, inspirada na vestimenta militar, primeiro na região de Flandres e entre os cavaleiros, depois no restante do Ocidente e por outros estados (PIPONNIER, 1989: 233). ${ }^{11}$

As mudanças e as ornamentações nas formas das vestimentas não deixaram de provocar queixas diversas dos tratadistas eclesiásticos. A crítica dos eclesiásticos respaldava-se no lugar que elas ocupavam no mundo terreno. A origem das vestes, retomada a partir da leitura do Gênesis $(3,7)$ e das considerações sobre a graça dos primeiros pais (BARTHOLEYNS, 2009: 101, 116), contribuiu para a delimitação de alguns princípios das vestimentas, sua consequente valorização e mesmo vinculação ao plano terreno. Em linhas

\footnotetext{
${ }^{10}$ Sobre o desenvolvimento têxtil em Castela, ver MARTÍNEZ MARTÍNEZ, 1988. A respeito da atuação régia quanto aos gastos nos trajes: GONZÁLEZ ARCE, 1998.

${ }_{11}$ A respeito da percepção dos moralistas das novidades nos trajes, ver: BLANC, 1989: 243253.
} 
gerais, os tratadistas afirmavam que, no Paraíso - onde não havia fome, sede e quaisquer outras necessidades -, as vestes eram dispensáveis, uma vez que os primeiros homens eram revestidos de graça divina (TALAVERA, 2001: 30). No entanto, a falta de Adão e Eva abriu-lhes os olhos e fez notar seus corpos, obrigando-lhes a esconder as vergonhas com folhas de figueiras. Nascia, desse modo, após o pecado - e com a finalidade de esconder as partes vergonhosas a 'primeira vestidura que houve no mundo' (TALAVERA, 2001: 29). Ainda segundo a narrativa bíblica, após a expulsão dos primeiros pais do Paraíso, Deus os teria coberto com peles; as quais, de acordo com Ludolfo de Saxônia, por serem de animais mortos, simbolizariam a própria mortalidade da qual se revestiam os homens, destituídos já de toda a graça (LUDOLPHUS DE SAXONIA, 1503, v. 2: 114v).

$\mathrm{O}$ vestir configurava-se, nessa perspectiva, como elemento definidor da condição dos homens na terra a partir da Queda (BARTHOLEYNS, 2009: 103), momento em que os primeiros pais desobedeceram a Deus, e cumpria algumas funções no plano terrestre. Tomando parte da leitura do Eclesiástico $(29,21){ }^{12}$ o agostiniano Egídio Romano, por exemplo, compreendia o vestir como uma das quatro necessidades naturais dos homens (GLOSA, 2005: 330-331). ${ }^{13}$ Glosando a mesma passagem de Egídio Romano, García de Castrojeriz considerava que o vestir cumpria quatro funções, que tiveram longa duração e circulação entre os letrados castelhanos: 'cobrir os corpos e escusar a desnudez, que [era] coisa de grande vergonha'; 'escusar o frio'; 'departir as companhias'; 'adornar o corpo' (GLOSA, 2005: 639-640). Era, portanto, a partir destas características naturais atribuídas ao vestir que os tratadistas estabeleciam suas prédicas e descreviam as práticas consideradas boas ou más. Dessas funções, contudo, interessa observar em pormenores a de exteriorizar o estado das pessoas; função que, fosse por excesso, fosse por míngua, motivou queixas diversas.

\footnotetext{
${ }^{12}$ Passagem também presente em Talavera (2001: 29) e Madrigal (1507, v. 5: 50v).

${ }^{13}$ As outras três seriam: comer, proteger-se e doutrina.
} 
A concepção de que a veste traduzia externamente o interior do homem não era nova e respaldava-se sobretudo no livro do Eclesiástico $(19,27)$. Por tal espelhamento, era de grande importância que o exterior se conformasse com o interior e correspondesse à diferença natural entre as pessoas. Para os eclesiásticos, e certamente também para os leigos, era imprescindível manter uma diferença entre os estados por meio das vestimentas, pois a distinção era dada por Deus. Afinal, as vestes traduziam exteriormente aquilo que a pessoa era. Por meio delas era possível reconhecer um clérigo ou leigo, um cavaleiro ou mesteiral, ou mesmo a religião e a crença dos homens. Desrespeitar as diferenças ou os usos apropriados das vestimentas significava, portanto, desprezo pela vontade divina. Em decorrência disso, foram comuns as queixas relativas aos gastos excessivos com as vestes e às confusões na aparência entre pessoas de estados distintos, sobretudo nestes dois séculos com a profusão de novos vestidos, tecidos e ornamentos.

Os excessos e as confusões, frequentemente denunciados nas cortes, ${ }^{14}$ não ocorriam apenas entre estados diferentes, isto é, entre cavaleiros e mesteirais e suas respectivas mulheres, ou entre as mulheres casadas e aquelas que viviam em relacionamentos não sacramentados, mas igualmente entre eclesiásticos e leigos e entre cristãos, judeus e muçulmanos (MARTÍNEZ MARTÍNEZ, 2003: 41). As novidades nos trajes, concebidas por esses homens muitas vezes como excessivas e escandalosas, não se limitaram aos estados dos leigos, circulando entre os próprios eclesiásticos, sobretudo os seculares. De maneira similar à regulação das vestes dos súditos, o que incluía judeus e mouros, regulação que era uma competência atribuída às autoridades seculares, ${ }^{15}$ os cuidados com as vestes do clero, quando não se encontravam expressos no direito canônico ou na regra da ordem religiosa, tornavam-se assunto dos concílios e sínodos. Ainda que o foco do presente estudo seja a tratadística, as constituições decorrentes dessas reuniões merecem aqui uma

\footnotetext{
${ }^{14}$ Uma breve descrição desses artigos de cortes pode ser encontrada em: GONZÁLEZ ARCE, 1998: 26-28.

${ }^{15}$ Sobre a atuação dos monarcas, ver: GONZÁLEZ ARCE, 1998. E sobre a complementaridade da atuação eclesiástica às disposições seculares: MARTÍNEZ MARTÍNEZ, 2006: 349.
} 
análise por constituírem uma das principais bases sobre as quais os tratadistas estabeleciam suas prescrições.

Um dos aspectos que distinguia o clero do leigo era o uso da coroa e de vestes honestas e apropriadas ao culto religioso. Muitos clérigos, no entanto, dada a vivência no século, distinguiam-se pouco ou quase nada dos leigos. Foram, por isso, recorrentes as denúncias de que não respeitavam as regras e constituições, fosse no corte de cabelo, fosse no uso de vestes preciosas, fosse, ainda, no trazer das vestes desonestas e impróprias ao ofício. Zelar pelo cumprimento dessas regras era uma tarefa dos prelados, incumbência reafirmada nos concílios e sínodos. No concílio de Valladolid, celebrado no ano de 1322, o bispo de Sabina e legado papal, D. Guillermo de Godin, declarou que os prelados deveriam, em primeiro lugar, cuidar para que seus súditos observassem neles 'santidade de vida e bons costumes' (CONCILIO, 1851c: $480),{ }^{16}$ o que exigia dos clérigos, maiormente dos prelados, entre outras coisas, 'honestidade no trato, no hábito e no traje' (CONCILIO, 1851c: 482). Tal honestidade era ainda mais exigida em relação aos arcebispos e bispos, 'porque em virtude de sua[s] dignidade[s] deve[ria]m servir de espelho a outros', isto é, os demais clérigos por meio deles aprenderiam a maneira conveniente de se portar na 'casa do Senhor' (CONCILIO, 1851c: 482). No mesmo concílio de 1322, permitiu-se aos bispos e prelados superiores o uso de roupas de lenço e se estipulou que, quando estivessem a cavalo, não usassem 'tabardos, senão capas redondas'; além disso, deveriam trazer os 'cabelos arrumados à sua dignidade' e não gastar com 'capas ou vestidos de seda' (CONCILIO, 1851c: 482). A recorrência do capítulo sobre a vida e a honestidade do clero nessas reuniões se amparava na consideração de que a honestidade tão requerida nos costumes dos clérigos se manifestava, segundo o sínodo de Toledo de 1326, 'principalmente no traje', ou seja, no hábito e na tonsura (CONCILIO, 1851b: 528). No sínodo de Cuenca de 1446, por sua vez, o bispo D. Lope de Barrientos (1382-1469) esclarecia que todos os homens deveriam guardar-se 'de toda semelhança do

\footnotetext{
${ }^{16}$ Os textos dos concílios encontram-se em latim. Cita-se aqui a partir da tradução castelhana realizada pela edição bilíngue, preparada por Tejada y Ramiro.
} 
mal', especialmente os clérigos, pois deveriam 'ter grande honestidade no seu trajar e em seu vestir', por servirem tais boas práticas 'como sinal [de] onde todos os outros dev[ia]m tomar exemplo' (LIBRO, 2011: 227).

A permissão de uso de melhores vestimentas aos homens de maior estado amparava-se na concepção de que elas davam a conhecer a dignidade da pessoa. Havia, portanto, equivalência entre a quantidade, a qualidade e a dignidade das vestes (MARTÍNEZ MARTÍNEZ; LORA SERRANO, 2007: 203). Era preciso evitar, contudo, que tais vestimentas, destinadas a princípio a dignificar o estado eclesiástico, dessem ocasião a excessos concebidos como pecados. As reiterações frequentes das decisões conciliares contrárias à superfluidade dos trajes e hábitos eclesiásticos pareciam indicar que os cânones não tiveram os efeitos desejados e que muitos clérigos seculares, mesmo quando traziam hábitos próprios, pecavam no descomedimento. As constituições do concílio provincial de Toledo de 1324, por exemplo, proibiam os descuidos nos trajes dos clérigos, especialmente as sobretúnicas e os tabardos excessivamente longos a ponto de serem arrastados, o que era 'supérfluo e indecente'. Do mesmo modo, eram vedados os 'mantéus ou capas excessivamente largos, nem sujeitos com cordas' e proibiam-se as 'mangas tão curtas que descobr[isse]m os braços'. O clérigo que desrespeitasse tal regra deveria perder as referidas vestes (CONCILIO, 1851a: 522). Por vezes, não era o comprimento excessivo do hábito o alvo da crítica, mas, ao contrário, seu encurtamento. Segundo as constituições do concílio de Cuenca de 1446, os clérigos estavam proibidos de trazer 'vestiduras superficiais, curtas, nem apertadas, nem breves', e sim 'vestiduras comumente longas e honestas, de maneira que des[cesse]m da rodilha até o tornozelo, [e] que cobr[isse]m as vestiduras de baixo'. Entretanto, elas não deveriam ser de peles preciosas, tampouco custosas (LIBRO, 2011: 227). Não observar as maneiras corretas do hábito, conforme estabelecidas pelas regras ou pelos direitos, poderia, inclusive, acarretar a perda do 'privilégio dado aos clérigos sobre os leigos' (MADRIGAL, 1500: 15v). 
Os valores sobre os quais os prelados estruturavam seus cânones eram dados pela própria criação e pelo lugar que cada pessoa ocupava e constituíam elementos largamente retomados e difundidos na tratadística. As vestimentas dos eclesiásticos, explicava Talavera, assim como as dos letrados, anciãos e honrados, deveriam ser compridas como as das mulheres para guardarem maior vergonha e honestidade e para transmitirem 'gravidade, siso e madureza' (TALAVERA, 2001: 31-32). Quanto aos religiosos, 'de qualquer ordem que sejam, salvo as dos cavaleiros, trazem e hão de trazer hábitos de pano vil, áspero e depreciado, porque têm ofício e estado de fazer penitência por seus pecados e pelos do povo' (TALAVERA, 2001: 34). Daí os eclesiásticos não poderem descobrir quaisquer partes do corpo ou utilizarem-se de vestimentas que representassem algum excesso ou defeito. Assegurando vestes simples, sem adornos, sem excessos, sem contatos com as sujeiras, mas condizentes as suas dignidades - o que permitia, sobretudo ao clero no desempenho do ofício, trazer 'hábitos longos e pomposos' (TALAVERA, 2001: 32) -, os clérigos dariam de si bom exemplo, serviriam como espelho e honrariam os estados nos quais Deus lhes dispusera. Para tanto, era preciso que suas vestimentas se distinguissem das vestes dos leigos, especialmente dos varões, cujas roupas eram curtas por andarem pelos espaços públicos (TALAVERA, 2001: 31-32).

O zelo pela diferenciação entre as vestimentas de leigos e clérigos, deveria ser observado por todos e exigido pelos superiores leigos e eclesiásticos. De acordo com o agostiniano Egídio Romano, em seu De regimine principum, entre as coisas pelas quais o monarca se mostraria sábio era por meio do governo das gentes e das companhias, dando-lhes o provimento de suas necessidades. $\mathrm{O}$ tratadista religioso explicava que isso ocorreria se o monarca vestisse os seus 'honradamente segundo a maneira de seus estados e suas pessoas'. Nesse sentido, era preciso, além de distinguir clérigos e leigos por meio das vestiduras, diferenciá-los segundo suas condições: aos maiores, cabiam-lhes melhores vestes, aos menores, proporcionais e convenientes. Observar e respeitar a diferença era importante, 'porque nisto se mostra[va] a sabedoria do príncipe, assim como a sabedoria de Deus reluz[ia] na apostura de 
suas criaturas' (GLOSA, 2005: 634-635). Tratava-se, pois, de uma perspectiva compartilhada pelos prelados nos concílios e difundida entre os diversos meios de que as coisas foram criadas de formas diferentes umas das outras, cada qual com uma dignidade e merecedora de vestes adequadas.

Concebidas em uma ordem, as vestimentas não deveriam, pois, serem inferiores ao estado de quem as possuísse, tampouco superiores. Todavia, o excesso nos trajes, como visto mais acima, foi o aspecto a que os tratadistas mais se ativeram e aquele que mais aproximava leigos e eclesiásticos. Em todos os casos, o uso de trajes vistosos expressava apego mundano, afastava os cristãos da simplicidade proposta por Cristo e seus apóstolos e tornava-os propensos aos mais diversos pecados e delitos. Para o dominicano López de Salamanca, seguindo de perto as considerações de Ludolfo de Saxônia (LUDOLPHUS DE SAXONIA, 1503, v. 3: 106r), o apego às vestes preciosas era, entre outros pontos negativos, uma loucura, pois as vestes seriam oriundas da falta dos primeiros pais. Logo, trazer vestidos pomposos e apegar-se a eles seria como portar um 'sinal de traição ou de ladrões'. Ademais, era preciso desapegar-se das vestes preciosas pela maldade acarretada por elas, uma vez que, 'para vestir os maridos a suas mulheres e a si mesmos', os homens cometiam uma série de pecados e delitos, como rapinas, furtos e usuras (LÓPEZ DE SALAMANCA, 2004: 133). Por isso, vestir-se em demasia seria prática semelhante à do ladrão, que procurava ocultar a orelha cortada com o cabelo (TALAVERA, 2001: 30). Seguindo a mesma linha de raciocínio, o arcediago de Leão, Clemente Sánchez de Vercial, em seu Libro de los exemplos por A.B.C., destacava que, ao cuidar mais das vestimentas e dos adornos que da salvação, homens e mulheres provocariam a própria condenação. Isso decorria do fato de a mulher requisitar vestidos preciosos e o marido permiti-los, e mesmo incentivar a vaidade, fazendo com que o casamento em vez de contribuir para a salvação do casal e para o governo da casa, lançasse-o ao inferno (SÁNCHEZ DE VERCIAL, 2011: 208). As faltam são tantas que Talavera indaga: 'quem poderá contar, nem meio dizer, o estudo demasiado que se tem e teve no vestir, trazer e calçar, e os pecados de muitas maneiras: de 
soberba, de vaidade, de luxúria e dissolução, de prodigalidade e ambição, de rapinas e tempos perdidos que se cometem no tal'? (TALAVERA, 2001: 47).

Diante dessa origem pecaminosa do vestir, Hernando de Talavera destaca três coisas proveitosas de serem notadas. 'A primeira, que a demasia das vestiduras é culpável e se deve evitar como coisa não necessária e, por conseguinte, não natural'. A segunda, 'que é grande vaidade alguém apreciar-se de andar muito arroupado', uma vez que 'o pecado introduziu as vestiduras' (TALAVERA, 2001: 30). Vestir-se em demasia, a ponto de suar, enquanto outros andam nus e morrendo de frio, adverte Talavera, é 'coisa descomungada' (TALAVERA, 2001: 41). Ter muitas roupas era, inclusive, sinal de rapina e roubo, porque tudo o que era sobejo deveria ser doado aos pobres e necessitados. Sendo assim, não as dar seria o mesmo que as reter e roubar (TALAVERA, 2001: 41). Por fim, sobre a terceira coisa proveitosa a ser notada, diz Talavera, 'é desonesto e míngua de boa vergonha trazer descobertas algumas partes do corpo, as quais poderiam andar cobertas' (TALAVERA, 2001: 30). Esta última característica implicava, aliás, o próprio ato de vestir as outras pessoas, conforme estabelecido pelas obras de misericórdia corporais prática caridosa que reproduzia, de certo modo, o gesto misericordioso de Deus, que cobriu os primeiros homens com peles (PAIS, 1963, v. 2: 463). ${ }^{17}$

$\mathrm{O}$ apego às vestimentas adornadas, recriminado pelos eclesiásticos, também se expressava, entre outras medidas, pelo desenvolvimento técnico da arte de tecer, coser e fiar; o que despertava a curiosidade e a busca de novos materiais, afastando os homens da simplicidade cristã no vestir. Se no princípio eram folhas de figueiras, seguidas por peles de animais, passava-se, doravante, à utilização de vestes adornadas e coloridas, entre outras criações curiosas e vaidosas (LÓPEZ DE SALAMANCA, 2004: 133). Tornou-se, desse modo, tópica comum no Ocidente a de que havia uma corrupção dos homens, que passava pelas vestimentas, sobretudo nos séculos XIV e XV, quando os trajes

\footnotetext{
${ }^{17} \mathrm{O}$ bispo de Silves, Álvaro Pais, em seu tratado Speculum Regum, escrito em latim e dirigido ao monarca castelhano D. Afonso XI (1311-1350), apresenta a passagem como significativa de uma das manifestações das obras de misericórdia corporais, especificamente, vestir os nus (PAIS, 1963, v. 2: 463).
} 
assumiram mudanças cada vez mais significativas e céleres (HUGHES, 1990: 194; MARTÍNEZ MARTÍNEZ, 2003: 46). Se para os leigos, a busca por novos trajes, tecidos e panos de qualidades poderia dar ocasião de pecar, exigindo-se cuidados, para os religiosos, sobretudo, o cuidado era redobrado. A penitência e a constante vigilância dos religiosos sobre o corpo demandavam panos ásperos e leitos duros; entregar-se às 'vestiduras muito nobres e brandas' e dormir 'em cama muito branda', constituíam, segundo Madrigal práticas pecaminosas. Tais condutas eram escusáveis somente aos leigos, que não eram obrigados a uma vida rigorosa, sobretudo àqueles cujas compleições não suportavam outros tecidos e camas. Todavia, se a intenção do leigo fosse deleitar o corpo, cometiase pecado (MADRIGAL, 1500: 16r).

A progressão do uso de técnicas de tecer, coser e fiar poderia, por outro lado, ser compreendida como um atributo da razão humana, desde que não fosse movida pela vã curiosidade e pela busca de novidades para os deleites humanos. É isso que se deduz da discussão entre alguns tratadistas sobre a origem da arte de tecer e fiar. O bispo de Ávila e mestre-escola da Universidade de Salamanca, D. Afonso de Madrigal, em seu extenso comentário aos escritos de Eusébio de Cesareia (263-339), asseverava que o desenvolvimento das faculdades têxteis era decorrente da razão e que antecedia à deusa Minerva, considerada pelos antigos sua inventora. $\mathrm{O}$ ponto de partida do prelado seriam as vestes dadas aos homens por Deus para que sobrevivessem fora do Paraíso, no mundo terreno, pois, delas, os homens teriam criado e acrescentado novas técnicas (MADRIGAL, 1507, v. 4: 19v). ${ }^{18} \mathrm{O}$ tecer, o fiar e o coser constituíam, assim, algumas das indústrias necessárias para a sobrevivência dos homens, desempenhadas por meio da razão e que faziam parte daquilo que, à época, denominavam ofícios mulheris. Tratava-se de uma arte salutar, desde que usada racionalmente para cobrir-se e cobrir os outros, e sem qualquer intenção pecaminosa, contrária à razão ou à lei. (MADRIGAL, 1500: 8v, 14r-16r). Por isso, eram louvadas as mulheres, como Maria e a santa Isabel da Hungria

\footnotetext{
${ }^{18}$ A discussão também se dá em outros escritos seus (MADRIGAL, 1551: 248r). Sobre a temática em outros tratadistas, ver: MUÑOZ FERNÁNDEZ, 2014.
} 
(1207-1231) que se dedicaram a tecer e coser para vestir os pobres e para ornamento da Igreja.

\section{Vestir-se virtuosamente}

Uma das maneiras encontradas pelos tratadistas para contraporem-se à vaidade e à novidade nos trajes foi recorrer à concepção do vestir como necessidade natural, satisfeita razoavelmente. A premissa era a de que se vestir contrariamente à lei, à natureza e à razão era pecado (MADRIGAL, 1500: f. 14r). Talavera, por sua vez, reconhecendo a dificuldade de se julgar quais trajes eram 'supérfluos, tão excessivos e demasiados', propunha como regra observar o 'natural e razoável'. Por isso, a regra 'mais certa e mais geral' era pautar-se pela 'prudência e discrição do varão prudente e sábio' e, por conseguinte, acatar a decisão dos superiores (TALAVERA, 2001: 60). Entretanto, nos séculos XIV e XV, a variedade nas vestiduras era tal que, apesar das advertências dadas por Deus, Cristo e demais autoridades sobre os males e pecados oriundos da demasia no vestir, a conduta dos varões e das mulheres eram das mais reprováveis, pois havia entre eles, 'grande excesso [...] no trajar e no vestir'. Tais faltas decorriam do fato de "varões e mulheres de todo estado secular, [buscarem] mil maneiras e novidades de vestiduras e de trajes, novidades nas cores de muitas e diversas maneiras', afastando-se da 'simplicidade natural' que seria mais apropriada aos cristãos (TALAVERA, 2001: 45). Ao buscarem tais novidades e mudanças, os homens iriam igualmente contra a própria disposição das vestimentas, configurando, o maior ou menor afastamento ao que era 'natural e ordenado segundo a razão', pecado venial ou mortal (TALAVERA, 2001: 34). Portanto, os alfaiates e costureiros, se contribuíssem com a dissolução dos trajes, também eram passíveis de punições, como as dadas pelo prelado valhisoletano, e prescritas nos tratados de confissão, como o Libro de las Confesiones, de Martín Pérez, do início do século XIV, e a Suma de confesión llamada Defecerunt, do bispo D. Antonino de Florença (1389-1459), 
traduzida para castelhano no final do século XV (PÉREZ, 2002: 450-451, 474475; FLORENCIA, 1499: 117v).

Era tendo em vista o natural e o razoável que o prelado vallisoletano condenou as vestes desonestas que varões e mulheres traziam consigo. Os varões vestiam camisões bordados e muito ornamentados, diferentes e contrários à finalidade da camisa. Levando-se em consideração que as palavras remetiam à natureza das coisas, Talavera não deixava de lembrar que a palavra camisa ou camisão, segundo santo Isidoro de Sevilha (560-636), tinha o seu nome derivado de 'cama' (TALAVERA, 2001: 45). Tal aproximação evidenciava-se ainda mais ao se ter em conta que, no período em questão, estar apenas de camisa era considerado estar desnudo, ${ }^{19}$ pois ela era a peça mais próxima ao corpo, usada por baixo das outras vestimentas - 'para mais guardar a honestidade' - e para dormir (TALAVERA, 2001: 45). Assim, já não atendendo às funções naturais dos camisões, ou à simplicidade em seu vestir, Talavera recriminava o fato de os varões usarem-nos curtos, largos, rendados, plissados, e, ainda mais grave, com 'os cabeções como camisas de mulheres custosamente lavrados' (TALAVERA, 2001: 45). Apresentando, assim, características das vestes das mulheres e muitas variações de tecidos, tamanhos e cortes, os camisões afastavam-se da sua característica natural.

As vestimentas das mulheres foram igualmente recriminadas pelo prelado por modificarem o formato do corpo. Para além das transformações comuns aos outros reinos da Cristandade, em Castela, no século XV, surgiram duas peças do traje das mulheres, o chapim e o verdugo, que lograram larga circulação entre as castelhanas e ganharam destaque, inclusive, em outros reinos. ${ }^{20} \mathrm{O}$ chapim, calçado cuja sola era de cortiça (corcho), aumentava consideravelmente a altura da mulher e permitia o acréscimo de tecidos e outros adornos, encarecendo-o. Talavera teceu a este calçado inúmeras críticas, pois,

\footnotetext{
${ }^{19}$ Como esclarecia Bernís Madrazo (1955: 21), estar nu não significava apenas estar desprovido de todas as roupas. Trajar apenas algumas peças, como a aljuba, a camisa ou o gibão bastava para uma pessoa ser considerada nua.

${ }^{20}$ Sobre essas peças, ver: BERNÍS MADRAZO, 1978, v. 1; MARTÍNEZ MARTÍNEZ, 2006: 346. A respeito da importância das vestes ibéricas em um momento posterior, ver: LUIS COLOMER; DESCALZO, 2014.
} 
além de considerá-lo caro, o hieronimita acreditava que ia contra a disposição natural dos corpos das mulheres, corpos esses que deviam ser menores que os dos varões (TALAVERA, 2001: 40). A diferença na altura traduzia o princípio de superioridade dos varões para com as mulheres; o aumento da estatura das mulheres por meio de artifícios, prejudicava e colocava em risco a própria disposição natural. O verdugo, por sua vez, era um vestido largo, cosido com aros por baixo e com diversas faldetas, que motivou parte da crítica do prelado valhisoletano e fez com que Talavera dedicasse uma parte inteira de seu tratado para recriminar seu uso. ${ }^{21}$ Não cabe aqui adentrar em todos os aspectos relativos às alterações nos trajes dos leigos, por ora é importante destacar que algumas peças e, sobretudo, as transformações vestuárias chamaram atenção de outros tratadistas e eclesiásticos. ${ }^{22}$ De todo modo, as mudanças nos trajes poderiam encaminhar os homens aos mais diversos pecados, e mesmo desrespeitar a ordem natural e a vontade divina, que fizeram homens e mulheres diferentes. $^{23}$

Rememorar o surgimento das vestes implicava, para além de justificar a simplicidade à qual todo cristão deveria ater-se, considerá-las como sinal de penitência e desapago aos bens terrenos. Para tanto, era preciso ter em vista as próprias vestes dadas por Deus (BARTHOLEYNS, 2009: 104), uma vez que Deus teria vestido aos primeiros pais com peles de animais na forma de túnicas, e não com ricas vestimentas, conquanto 'pudesse, se o quisesse, vesti[-los] de rico brocado' (TALAVERA, 2001: 43). Estreitando a relação entre o nome e o objeto, Talavera explica que estas vestes são chamadas túnicas, porque 'propriamente quer dizer tongas ${ }^{24}$ ou saias que fazem som cada [vez] que são manejadas e mexidas'. Assim, pelo seu nome, que remete à sua natureza, deduz-se que elas não possuem forros ou quaisquer outros adornos, sendo tais túnicas mais próximas a dos 'pastores, ou como as dos segadores ou de outros

\footnotetext{
${ }^{21}$ Talavera lista doze motivos para vedar seu uso (TALAVERA, 2001: 62-68). Um resumo das críticas ao verdugo pode ser encontrado em MARTÍNEZ MARTÍNEZ, 2003: 59.

${ }^{22}$ Para algumas apreciações morais sobre o vestir em Castela, ver: MARTÍNEZ MARTÍNEZ, 2003: 35-59; MARTÍNEZ MARTÍNEZ, 2006: 343-380.

${ }^{23}$ Sobre algumas relações entre varões e mulheres no tratado de Hernando de Talavera, ver: CODET, 2016: 137-146.

${ }^{24} \mathrm{O}$ mesmo que túnica.
} 
pobres homens, ou daqueles carvoeiros que trazem carvão para vender em Salamanca' (TALAVERA, 2001: 43-44). Somente depois, e certamente para honrar o culto divino, Deus quis que o sacerdote, em especial o maior, "vestisse vestimentas de linho em certos dias e em outros de certo pano e cor, mas aquilo tudo era para significar certo mistério’ (TALAVERA, 2001: 44) - prática que, como visto anteriormente, era recomendada pelos cânones e pelas constituições.

A partir das considerações sobre o surgimento das vestes e das suas funções, os cristãos deveriam interiorizar certas virtudes e reconhecer as principais faltas. Como não havia uma regra no vestir, conforme reconhecia Talavera, o cristão deveria observar quando se afastava muito ou pouco do natural, interiorizar um mínimo de virtudes e reconhecer os pecados. Retomando as mesmas considerações de são Tomás de Aquino (1225-1274), expressas na Suma Teológica (II-II, q. 169, a. 1, rep), ${ }^{25}$ Talavera sintetizava as três virtudes para combater seus vícios: a humildade no vestir e no calçar para evitar a sobeja; a suficiência, como forma de evitar a jactância e contentar-se com o 'necessário e razoável', especialmente quando contradizia a condição ou estado; a simplicidade, para evitar as novidades e os males que delas decorriam (TALAVERA, 2001: 41, 44, 61-62).

Para que as boas condutas sobre o vestir fossem assimiladas mais facilmente pelos seus leitores e ouvintes, os tratadistas utilizaram-se de figuras exemplares. Escritos por clérigos e religiosos, esses textos, mesmo aqueles voltados à edificação de monarcas, apresentavam com frequência santos e santas, geralmente religiosos, como exemplares. Tratava-se, portanto, muitas vezes de traduzir ao público laico diversas regras de vestir oriundas dos meios monásticos, adaptando-as as suas necessidades. Entre as figuras rememoradas, são João Batista certamente foi um dos exemplos de vestir-se virtuoso e desapegado aos bens terrenos que mais se destacou nos escritos, em especial por ter recebido considerações favoráveis de Jesus. Sua vestidura de pelos de camelo e de um cinto de couro na cintura, a qual se somava uma alimentação

\footnotetext{
25 Talavera (2001: 58) menciona Tomás de Aquino entre os 'santos doutores modernos', destacando a sua postura favorável à proibição dos trajes desonestos.
} 
bastante rigorosa composta de mel silvestre e gafanhotos $(M t 3,4 ; M c 1,6),{ }^{26}$ contrapunha-se às vestes delicadas e vistosas e ao modo de viver daqueles que habitavam os palácios. O franciscano Juan García de Castrojeriz, por exemplo, ao destacar as formas pelas quais os moços deveriam ser instruídos no vestir, utilizou a imagem de são João Batista como contraponto às vestes daqueles que habitavam a casa régia e os palácios. O excerto utilizado pelo glosador, retirado do Evangelho de Lucas (7, 24-25), narra a passagem em que Jesus questiona os homens próximos ao profeta se saíram para ver 'homem bem vestido' no deserto. Decerto, não o encontrariam ali, pois, segundo Cristo, os homens que se vestiam 'bem e louçãmente', habitavam a 'casa dos reis'. Segundo o glosador, tal perspectiva sugeriria uma aceitação maior das vestes adornadas nos palácios que em outros lugares, desde que se evitassem a 'garzonía',27 e a desonestidade (GLOSA, 2005: 504). O cartuxo Ludolfo de Saxônia também teceu extensos comentários sobre as vestimentas ásperas deste 'perfeito varão [que] era são João', as quais serviriam para 'refrear a carne' e não deixar o corpo desnudo (LUDOLPHUS DE SAXONIA, 1502, v. 1: não paginado). Na tradução corrigida por Talavera da vida de Cristo escrita por Eiximenis, a santidade de são João Batista provava-se, além da alimentação, pela aspereza das vestes (EIXIMENIS, 1496: 84r), louvadas pelo próprio Cristo (TALAVERA, 2001: 57).

Outras menções similares sobre as vestimentas do profeta podem ser encontradas ao longo dos tratados castelhanos e com indicações sobre a importância das vestimentas para a comunidade dos homens. O dominicano López de Salamanca afirmava que as vestes do profeta atendiam somente à necessidade natural de ocultamento das vergonhas, já que elas não lhe protegiam do frio ou do calor, nem eram confortáveis ou adornadas para se ter um valor social. No caso do profeta, aliás, ressaltava o religioso, as vestes não

\footnotetext{
${ }^{26}$ Parece não haver consenso entre os tratadistas sobre o que seriam os gafanhotos. Para não delongar neste assunto, indicam-se aqui duas posições. Enquanto Ludolfo de Saxônia se refere aos gafanhotos (langostas) como ervas, uma vez que João Batista não comia carne ou pratos cozidos (LUDOLPHUS DE SAXONIA, 1502, v. 1: não paginado), Eiximenis diz serem 'vermes pequenos' (gusanos chiquillos), vocábulo que parece indicar o inseto (EIXIMENIS, 1496: 84r).

${ }^{27}$ Garzonía significa, entre outras coisas, a ‘vida dissoluta do jovem'. GARZONÍA, 2018.
} 
lhe eram necessárias, dada a sua santidade (LÓPEZ DE SALAMANCA, 2004: 132-133). Além das mesmas considerações sobre as vestes do profeta (MADRIGAL, 1551: 124r-124v), Madrigal recordava que, por não comer 'pão, nem carne, nem pescado, nem beb[er] vinho ou sidra, mas só mel campesino e gafanhotos' (langostas), e vestir-se com vestidura de peles de camelo considerada por Madrigal 'mais dura que cilícios' -, os homens viam em são João Batista 'sinal [de] ser divinal', uma vez que não fazia nada comum aos outros (MADRIGAL, 1551: 128v).

Os santos cumpriram igualmente papel importante para estabelecer práticas exemplares no vestir. Das santas, Talavera e Martín de Córdoba elogiaram santa Cecília, de origem nobre, e que, portanto, trazia vestes adornadas. A santa, porém, afastava de si qualquer vaidade, desapreciando os vestidos e castigando o corpo com cilícios, usados por baixo das vestes (TALAVERA, 2001: 43; CÓRDOBA, 1964: 99-100). Esta é a característica comum a quase todas as mulheres exemplares mencionadas pelos tratadistas, como as rainhas bíblicas Judite (Jdt 8, 6) e Ester (Est 4, 4) (GLOSA, 2005: 640; TALAVERA, 2001: 43, 50). A mesma postura de vestir-se adequadamente, mas sem quaisquer apreços mundanos, era ensinada e validada pelos 'santos cavaleiros que andavam no palácio, como são Martinho, são Sebastião, são Paulo e são João [...]' (TALAVERA, 2001: 43). Posturas como as destes santos respaldavam-se na consideração de que não poderiam negar o estado que ocupavam e trazer, por conseguinte, vestes inferiores. Trazer vestiduras ásperas só era condizente com aqueles que pregavam penitência, como são João Batista; querer utilizá-las para louvor próprio, por sua vez, era hipocrisia (CÓRDOBA, 1964: 99). Para esses tratadistas, os castelhanos poderiam tirar exemplos não apenas daquelas rainhas e desses santos nobres, mas, igualmente, de 'santo Tomás, arcebispo de Cantuária e de outros santos prelados', que traziam 'cilícios e ásperas vestiduras de monges debaixo daqueles hábitos honrados' (TALAVERA, 2001: 43). A prática de usar cilícios por baixo das vestimentas nobres era, inclusive, adotada por monarcas bíblicos, como o rei Jorão ( 2 Rs 6 , 30), que trazia vestes reais e cilícios por baixo delas (TALAVERA, 2001: 43). 
Todas essas pessoas exemplares traziam consigo vestes preciosas, para honrarem seus estados, conquanto não as apreciassem, e, por baixo delas, cilícios e panos ásperos, para evitar a vanglória ou qualquer vaidade pelos trajes. Ao conjugar a honra ao estado com práticas ascéticas, permitia-se, assim, que leigos incorporassem determinadas regras de conduta consideradas virtuosas em relação ao vestir, e evitassem a desonestidade nos trajes.

Havia, por fim, as figuras régias exemplares do período. Apesar das suas recriminações e da constatação de que sempre houve no mundo 'loucos', cuja felicidade era toda posta no vestir, Talavera ressaltava mudanças positivas, como a maior 'honestidade e modéstia', nos últimos vinte anos, coincidentes em grande parte com o reinado de D. Enrique IV (1425-1474), iniciado em 1454. Retomando uma tópica bastante difundida, expressada, sobretudo, no $D e$ regimine principum de Egídio Romano, o tratadista atrelava a boa conduta do reino à do próprio monarca, pois, 'honestando sua real pessoa e seguindo nisto o natural e verdadeiro, fez honestar a todo o reino'. Nesse sentido, as boas ou más ações do monarca espelhar-se-iam no reino. Daí recordar que, na Grécia, o rei é chamado de 'basileu, que quer dizer pilar do povo, porque se o rei está direito, ordenado e honesto tal está todo o povo, que se mantém sobre ele'. Contrariamente, 'se o rei declina e se inclina a qualquer vício grande ou pequeno também se inclina e declina atrás dele o povo' (TALAVERA, 2001: 47). Tal relação era tão importante que, para Talavera, seria 'muito de considerar e ainda muito de chorar aos príncipes que não [eram] bons', uma vez que arrastariam consigo todos ao pecado e os condenariam aos infernos; os príncipes bons, por sua vez, alçariam a si próprios e aos seus aos céus (TALAVERA, 2001: 47-48).

As mudanças positivas na conduta dos castelhanos em relação ao vestir, no entanto, eram, na perspectiva de Talavera, restritas aos varões - espelhando ao monarca -, pois 'quanto às donas grandes e pequenas muito, e mais que muito, cresceu a dissolução em seu tempo' (TALAVERA, 2001: 47). Para o prelado, neste assunto das vestimentas, 'muito mais excedem e pecam as mulheres na maneira de seu trajar, toucar, vestir e calçar, e em todo o atavio de 
suas pessoas [...]', não deixando igualmente de ressaltar o quanto falar sobre a temática era 'coisa vergonhosa e muito curiosa', e que Isaías, os profetas e os santos apóstolos reprovavam a demasia no vestir das mulheres. As dissoluções nos trajes eram tais que, à semelhança destas autoridades bíblicas, se sentia obrigado a repreendê-las e deixar de lado os pormenores, pois se dissesse todos, 'nunca acabaria'. No entanto, reconhecia que diante das faltas, 'se calássemos nos falariam as pedras, como diz o Santo Evangelho' (TALAVERA, 2001: 48). Apesar de não poupar os homens de suas críticas, Talavera, assim como outros religiosos, criticava mais a curiosidade delas, a celeridade das mudanças e a introdução das novidades surgidas nos trajes das mulheres no século $\mathrm{XV}$, entre as quais destacava-se o verdugo, surgido em 1468. Quanto a esta peça, cabe destacar um aspecto que não parece ter sido ignorado por Talavera, conquanto desconsiderado no Tratado provechoso. Segundo o cronista Afonso de Palência (1423-1492), o verdugo teria surgido da necessidade da rainha D. Joana de Portugal (1439-1475) em ocultar um segundo filho adulterino, sendo rapidamente seguida pelas damas da corte. Por ser cosido com largos aros e muito pano, o verdugo permitia ocultar a gravidez (PALENCIA, 1905, t. 2: 171-172). ${ }^{28}$ Sendo assim, se D. Enrique IV apresentava-se como o basileu, honestado a si, à coroa e aos súditos varões por meio das suas vestimentas; a rainha dava de si pouco exemplo e incitava outras mulheres a pecarem. Residia aí a importância de se estimular as boas condutas dos governantes e daqueles que exercessem ofícios de regimento, para que os súditos e fiéis se espelhassem neles e tomassem bom exemplo.

\section{Considerações finais}

Ao longo dos séculos XIV e XV, como visto, diversos eclesiásticos castelhanos procuraram estimular práticas virtuosas no vestir dos fiéis. Os escritos edificantes, fossem eles originários ou não do reino, fossem traduzidos

\footnotetext{
${ }^{28}$ Considerações sobre o verdugo, ver: BERNÍS MADRAZO, 1978, v. 1: 38-42; MARTÍNEZ MARTÍNEZ, 2006: 351.
} 
em vernáculo ou circulassem em latim, elencaram e sistematizaram uma série de cuidados que os cristãos deveriam ter com as vestimentas para não prejudicarem a si e aos outros, nem ofenderem a Deus. Evitando-se toda forma de excesso ou descuido com as vestes, os cristãos exteriorizariam aquilo que, de fato, eram, dariam de si bom exemplo e garantiriam a salvação da alma. As más práticas, por sua vez, não afetavam apenas aqueles que se vestiam desordenadamente, acarretando graves consequências à toda comunidade; especialmente, se os maus costumes estivessem presentes entre as autoridades eclesiásticas e seculares, responsáveis por conduzirem os fiéis e súditos por meio de seus exemplos. Para melhor fixarem os modos de condutas, foram fundamentais as vidas exemplares de religiosos, santos e senhores laicos - os quais, por suas condutas corretas, ensinavam aos demais a maneira mais virtuosa de se portarem. Necessidade natural dos homens na terra, o vestir comportava diversas outras atribuições na comunidade dos homens, as quais deveriam sempre prezar pelas práticas apropriadas aos cristãos, sendo imprescindíveis tais escritos edificantes para o estabelecimento de uma moral do vestir.

\section{Referências}

BARTHOLEYNS, G. L'enjeu du vêtement au Moyen Age: de l'anthropologie ordinaire à la raison sociale (XIIIe-XIVe siècles). Micrologus, n. 15, p. 219257, 2007.

L'homme au risque du vêtement. Un indice d'humanité dans la culture occidentale. In: Idem et al (dirs.). Adam et l'Astragale. Essais d'anthropologie et d'histoire sur les limites de l'humain. Paris: Éditions de la Maison des sciences de l'homme, 2009.

BERNÍS MADRAZO, C. Indumentaria medieval española. Madrid: Instituto Diego Velázquez del Consejo Superior de Investigaciones Científicas, 1955.

Trajes y modas en la España de los Reyes Católicos. Madrid: Instituto Diego Velázquez del Consejo Superior de Investigaciones Científicas, 1978-1979, 2 v.

BLANC, O. Vêtement féminin, vêtement masculin à la fin du Moyen-Age: le point de vue des moralistes. In: PASTOUREAU, M. (dir.). Le vêtement, histoire, archéologie, symbolique vestimentaire au Moyen-Age. Paris: Le Léopard d'or, 1989. 
CASTRO, T. de. El tratado sobre el vestir, calzar y comer del arzobispo Hernando de Talavera. Espacio, Tiempo, Forma, Serie III, Historia Medieval, n. 14, p. 11-92, 2001.

CONCILIO de Toledo del año 1324. In: COLECCION de canones y de todos los concilios de la Iglesia española, traducida al castellano con notas é ilustraciones por D. Juan Tejada y Ramiro. Parte Segunda. Madrid: Santa Coloma y Peña, impresores del Ministerio de Comercio, instruccion y obras públicas, 1851a, t. 3.

CONCILIO de Toledo del año 1326. In: COLECCION de canones y de todos los concilios de la Iglesia española, traducida al castellano con notas é ilustraciones por D. Juan Tejada y Ramiro. Parte Segunda. Madrid: Santa Coloma y Peña, impresores del Ministerio de Comercio, instruccion y obras públicas, $1851 b$, t. 3.

CONCILIO de Valladolid del año 1322. In: COLECCION de canones y de todos los concilios de la Iglesia española, traducida al castellano con notas é ilustraciones por D. Juan Tejada y Ramiro. Parte Segunda. Madrid: Santa Coloma y Peña, impresores del Ministerio de Comercio, instrucción y obras públicas, 1851c, t. 3.

CODET, C. Hembras, varones y criaturas intermedias en el Tratado sobre la demasía del vestir de Hernando de Talavera. Cahiers d'études hispaniques médiévales, n. 39, v. 1, p. 137-146, 2016.

CÓRDOBA, M. de. Jardín de nobles doncellas. In: BIBLIOTECA de Autores Españoles. Madrid: Real Academia Española, 1964, t. 171.

COROMINAS, J. Breve diccionario etimológico de la lengua castellana. Madrid: Editorial Gredos, 1987.

CRAS, A. La symbolique du vêtement dans la Bible: pour une théologie du vêtement. Paris: Les Éditions du Cerf, 2011.

DÍEZ GARRETAS, M. J.; FRADEJAS RUEDA, J. M.; ACERO DURÁNTEZ, I. Aproximación a la traducción castellana del "De regimine principum" de Gil de Roma: estado de la cuestión y análisis de las versiones. Incipit, n. 24, pp. 1737, 2004.

DISCÍPULO. In: COROMINAS, Joan. Breve diccionario etimológico de la lengua castellana. Madrid: Editorial Gredos, 1987.

EIXIMENIS, F. Libro de la vida de Ihesu Christo añadido por Fr. Hernando de Talavera. Granada: Meynardo Ungut y Johannes de Nurenberga, 1496. 
FLORENCIA, A. Summa de confession llamada Defecerunt de fray Antonio arçobispo de florencia del orden de los predicadores. Burgos: Fadrique de Basilea, 1499.

GARZONÍA. In: DICCIONARIO de la lengua española. Disponível em: $<$ http://dle.rae.es/?id=IyQ3Tqp>. Acesso em: 29 nov. 2018.

GLOSA Castellana al "Regimiento de Príncipes" de Egidio Romano. Edición, estudio preliminar y notas de Juan Beneyto Pérez. Madrid: Centro de Estudios Políticos y Constitucionales, 2005.

GONZÁLEZ ARCE, J. D. Apariencia y poder. La legislación suntuaria castellana en los siglos XIII-XV. Jaén: Universidad de Jaén, 1998.

HUGHES, D. O. As modas femininas e seu controlo. In: DUBY, G.; PERROT, M. (dirs.). História das mulheres no Ocidente. Porto: Afrontamento, 1990, v. 2.

LIBRO sinodal y sínodo de Lope de Barrientos, 19 junio 1446. In: SYNODICON Hispanum. Edición crítica dirigida por Antonio García y García. Madrid: Biblioteca de Autores Cristianos, 2011, v. 10.

LÓPEZ DE SALAMANCA, J. Evangelios moralizados. Edición, introducción y notas de Arturo Jiménez Moreno. Salamanca: Ediciones Universidad de Salamanca, 2004.

LUDOLPHUS DE SAXONIA. Vita cristi cartuxano roma[n]çado por fray Ambrosio. Alcalá de Henares: Stanislao de Polonia, 1502-1503, 4 v.

LUIS COLOMER, J.; DESCALZO, A. (dirs.). Vestir a la española en las cortes europeas (siglos XVI y XVII). Madrid: Centro de Estudios Europa Hispánica, 2014, 2 v.

MADRIGAL, Alfonso de. Aquí comiença la quarta parte del come[n]to de Eusebio. Salamanca: Hans Gysser, 1507.

. Aquí comiença la quinta parte del comento de Eusebio. Salamanca: Hans Gysser, 1507. 1500. Co[n]fessional del Tostado. Burgos: Fadrique [Biel] de Basilea,

Las XIIII questiones del Tostado: a las quatro dellas por marauilloso estilo recopila toda la sagrada escriptura. Las otras diez qvestiones poeticas son acerca del linaje y sucession, de los dioses de los Gentiles [...]. Anvers: en el vnicornio dorado a costa de Martin Nucio imprimidor jurado, 1551.

MARTÍNEZ MARTÍNEZ, M. Indumentaria y sociedad medievales (ss. XIIIXV). En la España medieval, v. 26, p. 35-59, 2003. 
La creación de una moda propia en la España de los Reyes Católicos. Aragón en la Edad Media, n. 19, p. 343-380, 2006.

La industria del vestido en Murcia (ss. XIII-XV). Murcia: Academia Alfonso X el Sabio/ Cámara de Comercio, Industria y Navegación, 1988.

; LORA SERRANO, G. Las inversiones suntuarias de la nobleza a fines de la Edad Media. In: VILAR, J. B.; PEÑAFIEL RAMÓN, A.; IRIGOYEN LÓPEZ, A. (coords.). História y sociabilidad: homenaje a la profesora María del Carmen Melendreras Gimeno. Murcia: Universidad de Murcia, 2007.

MUÑOZ FERNÁNDEZ, A. Las cuestiones de Minerva. Problemata en torno a la acción femenina en los debates culturales del siglo XV castellano. In: GARCÍA HERRERO, M. del C.; PÉREZ GALÁN, C. (coords.). Mujeres de la Edad Media: actividades políticas, socioeconómicas y culturales. Zaragoza: Institución "Fernando el Católico", 2014.

PAIS, A. Espelho dos Reis. Estabelecimento do texto e tradução do Dr. Miguel Pinto de Meneses. Lisboa: Instituto de Alta Cultura, 1955-1963, 2 v.

PALENCIA, A. de. Crónica de Enrique IV. Madrid: Tipografia de la "Revista de Archivos", 1905, t. 2.

PARRILLA, C. La "seca" de la Tierra de Campos y el Tratado provechoso de Hernando de Talavera. In: HARO CORTÉS, M. (ed.). Literatura y ficcíón: "estórias", aventuras y poesía en la Edad Media. Valencia: Universitat de València, 2015, v. 1.

PÉREZ, M. Libro de las confesiones. Una radiografía de la sociedad medieval española. Edición crítica, introducción y notas por Antonio García y García, Bernardo Alonso Rodríguez e Francisco Cantelar Rodríguez. Madrid: Biblioteca de Autores Cristianos, 2002.

PIPONNIER, F. Une révolution dans le costume masculin au XIVe siècle. In: PASTOUREAU, M. (dir.). Le vêtement, histoire, archéologie, symbolique vestimentaire au Moyen-Age. Paris: Le Léopard d'or, 1989.

SÁNCHEZ DE VERCIAL, C. Libro de los exemplos por A.B.C. In: GUTIÉRREZ MARTÍNEZ, M. del M. Edición del Libro los exemplos por A.B.C. (2 $2^{\text {a }}$ parte). Memorabilia, v. 13, p. 1-216, 2011.

TALAVERA, H de. Tractado prouechoso que demuestra como en el vestir y calçar comunmente se cometen muchos pecados. Y aun tan bien en el comer y en el beuer. Hecho y copilado por el licenciado Fray Hernando de Talauera indigno prior entonces del monesterio de sancta maria de prado que es 
extramuros de la noble villa de valladolid. Y despues primero arçobispo de la santa yglesia de granada. Y confessor de la muy catholica reyna de españa Doña Ysabel primera deste nombre. In: Idem. Breue y muy prouechosa doctrina de lo que deue saber todo christiano con otros tractados muy prouechosos: conpuestos por el Arçobispo de Granada. [Granada: Meinardo Ungut y Juan Pegnitzer], 1496.

Tractado prouechoso que demuestra commo en el uestir y calçar comunmente se cometen muchos peccados. y aun tanbien en el comer y beuer [...]. [S. 1.: s. n., 14--]. REAL BIBLIOTECA DEL MONASTERIO DE SAN LORENZO DE EL ESCORIAL. Manuscrito $b-I V$-26.

Tratado provechoso que demuestra como en el vestir e calçar comunmente se cometen muchos pecados. In: CASTRO, T. El tratado sobre el vestir, calzar y comer del arzobispo Hernando de Talavera. Espacio, Tiempo, Forma, Serie III, Historia Medieval, n. 14, p. 21-71, 2001.

Recebido em: 12 de setembro de 2019

Aceito em: 14 de fevereiro de 2020 